\title{
NOVEL GADIS PANTAI KARYA PRAMOEDYA ANANTA TOER: SUATU KAJIAN DIMENSI GENDER
}

\author{
Yenny Puspita, Muhamad Nasir \\ email: yenny_puspita@yahoo.com \\ Dosen Universitas PGRI Palembang
}

\begin{abstract}
Abstrak - Tujuan penelitian ini adalah untuk mengetahui dan mendeskripsikan dimensi gender dalam novel Gadis Pantai karya Pramoedya Ananta Toer melalui tokoh Gadis Pantai. Metode yang digunakan adalah deskriptif kualitatif. Teknik pengumpulan data yang digunakan adalah teknik dokumentasi. Sumber data dalam penelitian ini adalah novel Gadis Pantai karya Pramoedya Ananta Toer yang terbit pada pada September 2011 cetakan ke tujuh yang diterbitkan oleh Lentera Dipantara dengan tebal 270 halaman. Teknik analisis data yang digunakan adalah teknik analisis karya. Berdasarkan hasil pembahasan dapat disimpulkan bahwa dari analisis dimensi gender melalui analisis kedudukan tokoh perempuan yaitu Gadis Pantai (Mas Nganten) ditemukan Mas Nganten memiliki sifat lemah atau inferior, yaitu lebih rendah dari laki-laki, ia merelakan dirinya hanya menjadi abdi suami, dan menjalankan perintah tentang apa yang boleh dan tidak boleh dikerjakan tanpa izin suami. Sedangkan melalui analisis kedudukan Bendoro, ditemukan bahwa Bendoro adalah seorang pembesar yang berkuasa. Meskipun ia dengan Mas Nganten dalam ikatan suami istri, ia tetap berkedudukan lebih tinggi dari Mas Nganten. la merupakan pemilik diri Mas Nganten yang berhak memberi peraturan tentang apa yang boleh Mas Nganten lakukan. Berdasarkan sikapnya, penulis menggambarkan kehadiran tokoh perempuan memiliki sifat lemah.
\end{abstract}

Kata Kunci: Dimensi gender, kedudukan tokoh perempuan, kedudukan tokoh laki-laki, dan sikap penulis.

Abstract-The purpose of this study is to find out and describe the gender dimensions in the novel Pantai Pantai by Pramoedya Ananta Toer through the character Pantai Gadis. The method used is descriptive qualitative. The data collection technique used is the documentation technique. The data source in this study is the novel Pantai Pantai by Pramoedya Ananta Toer, which was published in September 2011, the seventh print published by Lentera Dipantara, 270 pages thick. The data analysis technique used is the work analysis technique. Based on the results of the discussion it can be concluded that from the analysis of the gender dimension through the analysis of the position of the female character namely Pantai Pantai (Mas Nganten) it was found that Mas Nganten has a weak or inferior nature, which is lower than men, he volunteered himself to only be a servant of her husband, and carry out orders about what can and may not be done without the husband's permission. Meanwhile, through Bendoro's position analysis, it was found that Bendoro was a powerful figure in power. Even though he is with Mas Nganten in the bond of husband and wife, he still has a higher position than Mas Nganten. He is the owner of Mas Nganten who has the right to give rules about what he can do. Based on his attitude, the authors describe the presence of female characters as being weak.

Keywords: Gender dimension, position of female characters, position of male figures, and the attitude of the writer. 


\section{PENDAHULUAN}

Sastra merupakan cermin masyarakat. Keberadaan karya sastra tidak lepas dari masyarakat dan kenyataan sosial di sekelilingnya. Karya sastra hadir sebagai refleksi dari realitas sosial dan refleksi kesejarahan yang terjadi di masyarakat. Selain merupakan hasil imajinasi dari penghayatan pengarang, suatu hal yang tidak dapat dipungkiri adalah kenyataan bahwa seorang pengarang senantiasa hidup dalam suatu lingkungan sosial yang mendukungnya. Sehingga secara tidak langsung ia dapat menggambarkan atas apa yang dilihat dan rasakan pada karya yang dihasilkannya.

Sebagaimana dikemukakan juga oleh Golmand bahwa karya sastra diciptakan oleh pengarang sebagai hasil dari sebuah proses merespons situasi lingkungan dan sosialnya. Adanya karya sastra yang berangkat dari realitas, paling tidak memberikan penceritaan kepada masyarakat tentang sesuatu yang pernah terjadi pada masa tertentu.

Selain itu Endraswara (2013:15) memaparkan bahwa sastra itu adalah lembaga sosial yang menggunakan bahasa sebagai medium. Bahasa itu sendiri merupakan ciptaan sosial. Sastra menampilkan gambaran kehidupan dan kehidupan itu sendiri adalah suatu kenyataan sosial. Selanjutnya Semi (2012: 67) menyatakan sastra adalah suatu bentuk dan hasil pekerjaan seni kreatif yang objeknya adalah manusia dan kehidupannya menggunakan bahasa sebagai mediumnya.

$$
\text { Karya sastra berfungsi untuk }
$$
menginvestasikan sejumlah besar kejadian-kejadian yang telah dikerangkakan dalam pola-pola kreatifitas dan imajinasi. Sebagai karya yang imajiner, fiksi menawarkan berbagai permasalahan manusia dan kemanusiaan, hidup dan kehidupan. Pengarang menghayati berbagai permasalahan tersebut dengan penuh kesungguhan yang kemudian diungkapkan kembali melalui sarana fiksi sesuai dengan pandangannya. Fiksi merupakan hasil dialog, kontemplasi dan reaksi orang terhadap lingkungan dan kehidupan sehingga seorang pengarang akan mengajak pembaca memasuki pengalaman atau imajinasi melalui tokoh-tokoh dalam karya sastra (Nurgiyantoro, 2009:2-3).

Membicarakan sastra yang memiliki sifat imajinatif, kita berhadapan dengan tiga jenis (genre) sastra, yaitu prosa, puisi dan drama. Salah satu jenis prosa adalah roman. Roman adalah sebuah karya gambaran dunia yang diciptakan oleh pengarangnya, yang di dalamnya menampilkan keseluruhan hidup suatu tokoh beserta permasalahannya, terutama dalam hubungannya dengan kehidupan sosialnya.

Dalam perkembangan novel atau roman di Indonesia dari zaman dahulu sampai sekarang, banyak bermunculan novel atau roman yang bertemakan masalah-masalah yang berhubungan dengan perempuan. permasalahan itu terjadi karena perempuan cenderung dianggap lemah oleh laki-laki. (Sugihastuti, 2010:17) menambahkan bahwa penelitian tentang wanita dalam karya sastra merupakan penelitian tentang kehidupan wanita dan berbagai permasalahannya. Penelitian wanita diantaranya yaitu bagaimana pandangan pria terhadap wanita dan sebaliknya.

Novel yang menggambarkan atas apa yang dilihat dan rasakan pada karya yang dihasilkan pengarang, sebagai hasil dari sebuah proses merespons situasi lingkungan dan sosialnya tersebut adalah Gadis Pantai karya Pramoedya Ananta Toer. Gadis Pantai, sebuah karya yang dapat memberikan gambaran tentang permasalahan tokoh perempuan dalam 
sebuah keluarga yang berasal dari orang kebanyakan (miskin). Dengan mengangkat realitas kehidupan sosial masyarakat daerah pesisir pantai utara Jawa, Gadis Pantai mampu menghadirkan permasalahan itu ke dalam wujud karya sastra. Novel Gadis Pantai adalah kisah seorang gadis berusia 14 tahun yang tinggal di daerah pesisir pantai, yakni kampung nelayan. Gadis tersebut diperistri oleh seorang priyayi tinggi (Bendoro) akibat paksaan kedua orang tuanya, hingga membuat sang gadis merasakan ketidakmengertian dunia priyayi dan membuat dirinya menjadi warga kelas dua dalam kediaman Bendoro.

Novel Gadis Pantai dicetak pertama kali pada Juli 2003 dan telah enam kali dicetak ulang, berakhir pada September 2011.

Pramoedya Ananta Toer lahir pada 06 Februari 1925 di Kampung Jetis, Blora, Jawa Tengah, merupakan anak pertama dari ayah bernama Mastoer dan ibu bernama Oemi Saidah atau Siti Kadariyah. Pram memulai pendidikan formalnya di SD Blora, Radio Volkschool Surabaya pada tahun 1940-1941. Kemudian, melanjutkan ke Taman Dewasa/Taman Siswa pada 1942-1943. Lantas ke Kelas dan Seminar Perekonomian dan Sosiologi oleh Drs. Mohammad Hatta, Maruto Nitimihardjo dan Sekolah Stenografi 1944-1945, dan pernah ke Sekolah Tinggi, Islam Jakarta pada 1945. Pada akhirnya Pram wafat pada tahun 2006, tepatnya pada 30 April 2006, Pramoedya Ananta Toer wafat dikarenakan mengalami serangan Diabetes, sesak nafas dan jantung.

Beberapa karya Pramoedya Ananta Toer, memiliki ciri khas yaitu, karya Pram menceritakan seorang tokoh atau riwayat seseorang atau sebuah keluarga, karya Pram menguraikan persoalan sejarah, karya Pram bertendensi pada kemanusiaan serta nilai-nilai humanis. Pergulatan personal Pram atas kondisi sosial, ekonomi, budaya, politik adalah nilai humanis itu sendiri (Biografi singkat Pramoedya.2012. http://www.jendelasastra.com diunduh pada 26 Juli 2018).

Ciri khas di atas dapat kita lihat atau baca pada dua karya Pram yaitu, Larasati (2003), dan Panggil Aku Kartini Saja (2003). Larasati bercerita tentang perempuan bernama Larasati (Ara), seorang aktris, bintang film yang cantik pada masa-awal kemerdekaan Indonesia. la sangat terkenal di zaman Belanda. la ikut berjuang melawan penjajah "dengan caranya sendiri" yaitu dengan menghibur para pemuda yang berjuang melawan penjajah. Larasati adalah pelacur yang ingin bangsanya merdeka, memiliki keinginan kuat untuk melakukan perjuangan dengan simbol keartisannya. Sedangkan Panggil Aku Kartini Saja bercerita tentang seorang pribumi yang menolak dipanggil Raden Ajeng. Padahal ia adalah seorang putri bupati yang sebenarnya berhak menerima penghormatan itu. Tetapi, dalam suratnya perempuan itu menulis: "Panggil Aku Kartini Saja-itulah namaku!". Diam-diam ia sudah melakukan pemberontakan atas nilai-nilai kebudayaan Jawa yang feodalistik pada masa itu. Kartini juga menolak beasiswa belajar ke Belanda dan memohon agar beasiswa tersebut dialihkan saja kepada seorang pemuda Sumatera yang menurutnya pandai dan berbakat.

Berdasarkan uraian di atas dapat disimpulkan ada beberapa alasan mengapa memilih Gadis Pantai sebagai objek kajian adalah pertama roman Gadis Pantai dianggap sebagai sebuah karya sastra yang dapat menggambarkan tentang kehidupan tokoh perempuan dan permasalahannya, kedua karena karya Pram memiliki ciri bertendensi pada kemanusiaan atau menceritakan sebuah keluarga, ketiga karena roman ini telah mengalami tujuh kali cetak ulang. 


\section{Dimensi Gender}

Dimensi berarti parameter pengukuran yang dibutuhkan untuk mendefinisikan sifat-sifat suatu objek (Fakih, 2003:19). Selanjutnya, dimensi dapat diartikan sebagai matra, ukuran atau norma (Echols dan Sadily.2012:33) Gender adalah sifat yang melekat pada kaum laki-laki dan perempuan yang dibentuk oleh faktor-faktor sosial budaya, sehingga lahir beberapa anggapan tentang peran sosial budaya lakilaki dan perempuan. Kemudian kata gender berasal dari bahasa Inggris, yaitu gender yang berarti jenis kelamin (Fakih, 2003:167). Gender diartikan sebagai perbedaan yang tampak pada laki-laki dan perempuan dilihat dari segi nilai dan tingkah laku. Selanjutnya Fakih , (2003:169) mengemukakan bahwa gender adalah suatu sifat yang melekat pada laki-laki dan perempuan yang dikonstruksi secara sosial dan kultural. Lebih jelasnya gender adalah perbedaan prilaku (behavioral differences) antara laki-laki dan perempuan yang dikonstruksi secara sosial, bukan kodrat (ketentuan Tuhan), melainkan diciptakan oleh manusia melalui proses sosial kultural yang panjang. Jadi dimensi gender adalah norma dalam pensifatan yang melekat pada laki-laki dan perempuan yang dibentuk secara sosial dan kultural. Selanjutnya Fakih menguraikan bahwa perempuan di masyarakat dikenal lemah lembut, cantik, emosional, dan keibuan, sedangkan laki-laki dikenal kuat, rasional, jantan, dan perkasa. Cleves (2007:16-17), berpendapat bahwa sebagai batasan untuk mengungkap permasalahan feminis hanya dapat dikaitkan dengan gender, karena masih banyak perempuan yang mengalami ketidakadilan gender yang merupakan hak $\mathrm{m \epsilon} ;$ dalam memposisikan sama dengan laki-laki. $\mathrm{H}_{\mathrm{i}}$ terbukti bahwa kaum laki-laki khususnya yang masih berada dalam lingkungan patriarkal, mereka lebih banyak berperan sentral dalam segala urusan. Secara tradisional, masyarakat mengharapkan perempuan menjadi istri dan ibu Wolfman (dalam Sugihastuti, 2010:293). Kemudian secara global, perempuan masih identik dengan golongan miskin, lemah, dan hamil, serta dikodratkan secara sosial-budaya sebagai pendamping suami, pengelola rumah tangga, dan penerus keturunan. Perempuan dianggap sebagai mahluk yang lemah atau warga kelas dua, perempuan dibiasakan untuk tidak dapat menentukan nasibnya sendiri. (Sugihastuti, 2010:322) menyatakan bahwa perempuan dizamannya ditentukan untuk hanya mengikuti apa yang telah ditentukan sebagai suatu yang baik atau pantas baginya. Adapun yang menentukan baik atau tidak baik dan pantas atau tidak pantas itu adalah tradisi yang berlaku yang diwakili oleh kaum laki-laki (Ayah, suami, kakak laki-laki, dan masyarakat laki-laki). Laki-laki tidak mau menjadikannya sebagai teman, bahkan mereka ingin dianggap sebagai tuan oleh perempuan. Laki-laki cenderung memperlakukan perempuan (istri) sebagai benda yang dimilikinya, layaknya benda-benda yang lain Wahyuni (dalam Sugihastuti, 2010:218).

Dalam analisis gender, penelitian harus melibatkan kedua jenis seks manusia dalam mengungkap kehidupan tokoh perempuan. Dapat dilakukan pembandingan peran, status dan posisinya (Sugihastuti, 2010:23). Karya sastra yang menampilkan tokoh wanita bisa dikaji dari segi feminis. Baik cerita rekaan, lakon, maupun sajak mungkin untuk diteliti dengan pendekatan feminis. Asal saja ada tokoh wanitanya. Kita akan mudah menggunakan pendekatan ini jika tokoh wanita itu dikaitkan dengan tokoh laki-laki. Tidaklah menjadi soal apakah mereka berperan sebagai tokoh utama atau tokoh protagonis, atau tokoh bawahan, karena yang menjadi inti dari definisi feminis adalah perempuan (Sugihastuti, 2010:253). 
Adapun langkah-langkah untuk mengkaji sebuah karya sastra dengan menggunakan pendekatan feminis antara lain:

1. Mengidentifikasi satu tokoh perempuan, dan mencari kedudukan tokoh itu di dalam masyarakat;

2. Meneliti tokoh lain, tokoh laki-laki yang memiliki keterkaitan dengan tokoh perempuan yang sedang diamati;

\section{Metode Penelitian}

Metode yang digunakan dalam penelitian ini adalah metode deskriptif kualitatif. "Metode deskriptif ialah secara etimologis deskriptif berarti menguraikan. Tidak semata-mata menguraikan melainkan juga memberikan pemahaman dan penjelasan secukupnya" (Ratna, 2012:53). Sedangkan metode kualitatif adalah sebagai prosedur penelitian yang menghasilkan data deskriptif berupa kata-kata, atau tulisan dari orangorang dan perilaku yang diamati (Bogdan dan Taylor. Penulis menggunakan metode deskriptif dalam penelitian ini bertujuan untuk mendeskripsikan sifat yang melekat pada perempuan yang dikonstruksi secara sosial dan kultural.

\section{Hasil Penelitian}

Penelitian ini membahas tentang dimensi gender dalam novel Gadis Pantai karya Pramoedya Ananta Toer. Dimensi gender dapat dilihat dari kedudukan tokoh perempuan (Gadis Pantai) di dalam masyarakat, kedudukan tokoh laki-laki (Bendoro) di dalam masyarakat, dan sikap penulis karya yang sedang dikaji.

Dari analisis dimensi gender melalui analisis kedudukan tokoh perempuan yaitu Gadis Pantai (Mas Nganten) ditemukan bahwa Mas Nganten memiliki sifat lemah lembut atau inferior yaitu lebih rendah daripada laki-laki. Merelakan dirinya hanya menjadi abdi suami. Menjalankan perintah tentang apa yang boleh dan tidak boleh dikerjakan tanpa izin Bendoro.
Selanjutnya melalui análisis kedudukan tokoh Bendoro. Bendoro adalah seorang pembesar yang berkuasa. Suami Gadis Pantai. Meskipun dengan Mas Nganten dalam ikatan suami istri, ia tetap berkedudukan lebih tinggi daripada Mas Nganten. Merupakan pemilik diri Mas Nganten yang berhak memberi peraturan tentang apa yang boleh dilakukan oleh Mas Nganten. Kemudian dari análisis sikap penulis melalui nada dan suasana dengan kata-kata mendukung, menyindir, dan pesimis penulis menggambarkan kehadiran tokoh perempuan yang memiliki sifat lemah.

\section{Pembahasan}

Dari analisis dimensi gender melalui analisis kedudukan tokoh perempuan yaitu Gadis Pantai (Mas Nganten) ditemukan bahwa Mas Nganten memiliki sifat lemah lembut atau inferior yaitu lebih rendah daripada laki-laki. Merelakan dirinya hanya menjadi abdi suami. Menjalankan perintah tentang apa yang boleh dan tidak boleh dikerjakan tanpa izin Bendoro.

Selanjutnya melalui análisis kedudukan tokoh Bendoro. Bendoro adalah seorang pembesar yang berkuasa. Suami Gadis Pantai. Meskipun dengan Mas Nganten dalam ikatan suami istri, ia tetap berkedudukan lebih tinggi daripada Mas Nganten. la merupakan pemilik diri Mas Nganten yang berhak memberi peraturan tentang apa yang boleh dilakukan oleh Mas Nganten.

Berdasarkan análisis sikap penulis melalui nada dan suasana dengan kata-kata mendukung, menyindir, dan pesimis penulis menggambarkan kehadiran tokoh perempuan yang memiliki sifat lemah. Apabila dikaitkan dengan fenomena saat ini, novel Gadis Pantai adalah novel kontrafeminis, karena novel Gadis Pantai ini adalah novel yang bertentangan dengan semangat menyuarakan persamaan sepenuhnya antara perempuan dan laki-laki, serta menuntut 
adanya otonomi perempuan dan roman ini melanggengkan prasangka gender dalam penulisan dan pembacaan karya sastra.

\section{Simpulan}

Dimensi gender melalui tokoh Gadis Pantai (Mas Nganten) ditemukan bahwa perempuan sebagai istri, memiliki sifat lemah atau inferior yaitu berkedudukan lebih rendah daripada laki-laki yang merupakan warga kelas dua.

\section{Saran}

Berdasarkan simpulan di atas peneliti menyampaikan saran-saran :

1) Dimensi gender dalam novel Gadis Pantai karya Pramoedya Ananta Toer ditinjau dari sastra feiminis ini sangat baik untuk dibaca oleh guru, siswa, dan penikmat sastra yang ingin memperoleh tentang gender.

2) Dimensi gender ini sangat baik juga dibaca oleh peneliti lain sebagai acuan penelitian lebih lanjut.

\section{DAFTAR PUSTAKA}

Cleves, Julia Mosse. 2007. Gender \& Deveploment. (translated by Hartian Silawati). Yogyakarta: Pustaka Pelajar.

Arikunto, Suharsimi. 2002. Prosedur Penelitian Suatu Pendekatan Praktek. Yogyakarta: Rineka Cipta.

Darma, Yoce Aliah. 2009. Analisis Wacana Kritis. Bandung: Yrama Widya.

Djajanegara, Soenarjati. 2003. Kritik Sastra Feminis Sebuah Pengantar. Jakarta: Gramedia Pustaka Utama.
Endraswara, Suwardi. 2013. Metodelogi Penelitian Sastra: Epistemologi, Model, Teori dan Aplikasinya. Yogyakarta: CAPS

Fakih, Mansoer. 2003. dan Transformasi Sosial. Yogyakarta: Pustaka Pelajar Analisis Gender

Jabrohim. 2001. Metode Penelitian Sastra. Bandung: Angkasa.

Murniati, Nunuk P. 2004. Getar Gender (Buku Pertama). Magelang Indonesia Tera.

Nugroho, Riant. 2008. Gender dan Administrasi Publik. Yogyakarta: Pustaka Pelajar.

Nurgiyantoro, Burhan. 2009. Teori Pengkajian Fiksi. Yogyakarta: Gajah Mada University Press.

Pradopo, Rachmat Djoko. 2007. Pengkajian Puisi. Yogyakarta: Gadjah Mada University Press.

Ratna, Nyoman Kutha. 2012. Teori, Metode, dan Teknik Penelitian Sastra. Yogyakarta: Pustaka Pelajar.

Sugihastuti. 2000. Perempuan di Mata Perempuan. Bandung: Nuansa Cendekia.

Sugihastuti dan Suharto. 2010. Kritik Sastra Feminis Teori dan Aplikasinya. Yogyakarta: Pustaka Pelajar.

Sugono, Dendy. 2008. Kamus Besar Bahasa Indonesia. Jakarta: Gramedia.

Thornham, Sue. 2000.Teori Feminis dan Cultural Studies. Yogyakarta: Jalasutra

Toer, Pramoedya Ananta. 2011. Gadis Pantai. Jakarta: Lentera Dipantara. 